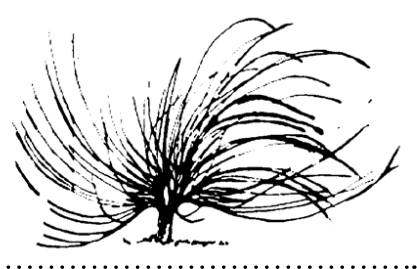

\title{
O percurso escrito da observação no estágio supervisionado à sua leitura no curso de Letras
}

\author{
Luana Clementino Chalegre ${ }^{l}$ \\ Faculdade de Letras e Ciências Humanas Universidade de São Paulo \\ Brasil \\ luana.chalegre@usp.br
}

\begin{abstract}
Resumo
O presente artigo busca verificar o modo como ocorre o registro ao longo do estágio supervisionado e mapear os pontos nos quais os licenciandos têm dificuldades em transmitir por escrito o que observaram em sala, nos diários de campo e relatórios de estágio. Enfatizamos a importância do registro do estágio supervisionado, e é preciso, para isso, contar com o planejamento de como ocorrerá o estágio, ou seja, ele não deve ocorrer espontaneamente, pois tal processo refletirá na formação reflexiva do futuro docente. Nesta empreitada, é de suma relevância o registro escrito, para que se organize o pensamento e, portanto, que os acontecimentos não se percam, obtendo-se, assim, dados de maior consistência, o que possibilita um diário de campo e um relatório mais fidedignos. De fato, não é uma atividade fácil observar e
\end{abstract}

http://dx.doi.org/10.15359/rep.esp-20-1.7

1 Mestranda em Letras na Faculdade de Filosofia, Letras e Ciências Humanas (FFLCH), da Universidade de São Paulo (USP), no Programa de Pós-Graduação em Filologia e Língua Portuguesa, sob a linha de pesquisa "Linguística textual e Teorias do Discurso no Português". Graduada em Letras pela Faculdade de Filosofia, Letras e Ciências Humanas (FFLCH) e Licenciada em Português pela Faculdade de Educação (FE), da Universidade de São Paulo (USP). Desde março de 2015, é um dos integrantes do projeto "A escrita sobre as práticas de ensino em licenciaturas do Brasil, da Costa Rica e de Honduras: registro, análise e produção de conhecimento" (Chamada Universal MCTI/CNPq N 14/2014). Realizou iniciação científica na Faculdade de Educação, sob a orientação do Prof. Dr. Valdir Heitor Barzotto (barzotto@ usp.br) entre março de 2015 a fevereiro de 2016, com o projeto "O registro escrito no estágio supervisionado no curso de Letras: as invisibilidades nos diários e relatórios”. 
registrar, pois esta atividade envolve e exige resistência e insistência, na busca de um texto coerente com as experiências vividas em sala de aula. O presente trabalho vem sendo desenvolvido na Iniciação Científica e está inserido no projeto "A escrita sobre as práticas de ensino em licenciaturas do Brasil, da Costa Rica e de Honduras: registro, análise e produção de conhecimento" (Chamada Universal MCTI/CNPq No 14/2014) ${ }^{2}$.

Palavras-chaves: estágio supervisionado, observação, dados, diários, relatórios e curso de Letras.

\begin{abstract}
This paper seeks to verify the way in which students' register occurs throughout their supervised internship and identify the difficulties that students have while communicating what they have observed in class in written form in their field diaries and their internship reports. We highlight the importance of keeping a record of the supervised internship, and to do this, it is necessary to plan how the internship is to be carried out. In other words, this activity cannot take place spontaneously because that would affect teachers' future reflexive training. Thus, written records are of the utmost importance to organize thoughts and not lose track of events, thereby obtaining consistent data, which allows having more reliable field diaries and reports. In fact, this is not an easy activity to observe and record since that implies and requires resistance and insistence in the search of a coherent text with the experiences lived in the classroom. This paper has been developed as part of the project $A$ escrita sobre as práticas de ensino em licenciaturas do Brasil, da Costa Rica e de Honduras: registro, análise e produção de conhecimento (Chamada Universal MCTI/CNPq No 14/2014).
\end{abstract}

Keywords: supervised internship, observation, data, diaries, reports, language course

2 O Ministério da Ciência, Tecnologia e Inovação - MCTI e o Conselho Nacional de Desenvolvimento Científico e Tecnológico - CNPq tornaram pública a presente Chamada, a fim de convidar interessados a apresentarem propostas que visassem contribuir significativamente para o desenvolvimento científico e tecnológico e inovação do país, em diferentes áreas do conhecimento, para que fossem selecionados projetos para apoio financeiro. 
"Uma verdadeira viagem de descoberta não é a de pesquisar novas terras, mas de ter um novo olhar." M. Proust

\section{Introdução}

$\mathrm{E}$ ste artigo se insere no projeto "A escrita sobre as práticas de ensino em licenciaturas do Brasil, da Costa Rica e de Honduras: registro, análise e produção de conhecimento" (Chamada Universal MCTI/CNPq No 14/2014), que articula três questões centrais: (1) de que forma textos escritos a partir das práticas de ensino funcionam enquanto registro de uma aula, (2) que tipos de trabalho podem ser realizados sobre o registro de uma aula, e (3) o que se afirma sobre uma aula com base no que foi registrado dela.

O objetivo central deste trabalho é verificar como ocorre o registro ao longo do estágio supervisionado e mapear os pontos nos quais os licenciandos têm dificuldades de transmitir por escrito o que observaram em sala, nos diários de campo/observação e relatórios de estágio.

É importante que o registro do estágio seja constante e é preciso, para isso, contarmos com o planejamento de como ocorrerá o estágio, ou seja, ele não deve ocorrer espontaneamente ${ }^{3}$, pois tal processo, além de possibilitar uma vivência única e profícua, certamente será fundamental na formação reflexiva do futuro docente.

Neste contexto, observa-se que as ações do estagiário transcendem o "dar, assistir a e anotar/registrar aulas"; ao longo do estágio, o aluno tem a oportunidade de questionar (-se), apresentar ideias e propostas, e desenvolver projetos. Nesta empreitada, é de suma relevância o registro escrito, para que se organize o pensamento e, portanto, que os acontecimentos não se percam:

Nossa memória não consegue guardar grande quantidade de informações existentes no mundo contemporâneo. Por isso registramos para que possamos rever o acontecido. E ao registrar o acontecido, fazemos a história, deixamos nossa marca no mundo, assim como os primeiros hominídeos. Como afirma Vygotsky, o

3 É importante que o aluno conheça a escola em que irá fazer o estágio, e saiba em quanto tempo pretende realizá-lo, o período (matutino, vespertino ou noturno) em que frequentará as aulas, as turmas e professore(s) que acompanhará (e que permitirão esse acompanhamento - que, não raro, é negado, inclusive pelo direito à autonomia que detêm o professor responsável por tais turmas) e que tenha um roteiro básico do que pretende anotar. 
que nos diferencia do animal é o exercício do registro da memória humana. Quando registramos, seja sob a linguagem verbal ou não verbal, nos apropriamos de nossa história, a nível individual e social (Vasconcelos, 2003, p. 70).

Desta forma, ao anotarmos, é maior a probabilidade de obtenção de dados com maior consistência, o que possibilita um diário de campo e observação $0^{4}$ e, consequentemente, um relatório ${ }^{5}$ mais fidedigno; caso o estagiário opte por observar e reger o número exigido de aulas e somente ao término dessas duas modalidades faça as anotações, perceberá que essa estratégia não é eficaz, tendo em vista os inúmeros detalhes que poderiam ter sido registrados em tempo e que muito provavelmente terão se perdido. De fato, não é uma atividade fácil "observar, apresentar, registrar, descrever e analisar", pois envolve e exige exercício disciplinado de persistência, resistência e insistência, na busca de um texto coerente com as experiências vivenciadas em sala de aula.

\section{Referencial teórico}

Para a escrita do diário de campo, já inserido no contexto escolar, o aluno pesquisador ora participa, ora não, das atividades do grupo em que está inserido; busca, simultaneamente, ver e ouvir com atenção, registrando da forma mais fiel possível os eventos; e ainda exercita o julgamento de decidir o que é pertinente registrar ou não em determinados momentos. Em relação a "pertinente", subjaz o entendimento de que a sala de aula é um cenário onde "mil coisas ocorrem ao mesmo tempo", onde, apesar de os cinco sentidos do pesquisador estarem em alerta, no momento do registro, tornam-se prementes certas escolhas, já que a visão, a audição e a velocidade da escrita humana - sujeitas sobretudo à dispersão por distrações, e à capacidade mnemônica individual de cada estagiário - apresentam sérias restrições. O observador,

4 Material composto ao longo do estágio, que consta de apresentação, descrição e análise dos dados colhidos na sala de aula para cada aula em que foi feita a observação, intervenção ou regência.

5 Material composto no final do estágio, que consta das reflexões dos dados obtidos ao longo do estágio. Neste momento, o aluno, além de refletir sobre os dados colhidos, cruza-os com o aporte teórico indicado pelo docente responsável pela disciplina (no caso específico do curso de Licenciatura da Universidade de São Paulo, a referida disciplina, desdobrada em dois semestres com estágio obrigatório, chama-se Metodologia do Ensino de Língua Portuguesa I e II, ou, abreviadamente, MELP I e II). No relatório, o aluno pode trazer suas descobertas, ideias e projetos suscitados. 
humano, não dispõe da mesma facilidade que um gravador de última geração e câmeras de alta resolução, conectados sincronicamente, proporcionariam ao estudo de uma sala de aula.

Fora de cogitação, entretanto, está o fato de se poder descrever, sem limites, todas as relações que possam assim aparecer. É preciso, numa primeira aproximação, aceitar um recorte provisório: uma região inicial que a análise revolucionará e reorganizará, se houver necessidade. Mas como circunscrever essa região? (...) É preciso ter em mente dois fatos: a análise dos acontecimentos discursivos não está, de maneira alguma, limitada a semelhante domínio; e, por outro lado, o recorte do próprio domínio não pode ser considerado como definitivo, nem como válido de forma absoluta; trata-se de uma primeira aproximação que deve permitir o aparecimento de relações que correm o risco de suprimir os limites desse primeiro esboço (Foucault, 2009, pp. 33-34).

Os dados coletados podem ser registrados na forma de narrativa, discurso direto e indireto, entretanto não se deve perder o ponto-chave da etnografia, que é a descrição densa e contextualizada do fenômeno observado. Conforme Angrosino (2009), o registro sistemático dá confiabilidade à observação participante. Ao longo das observações, torna-se possível verificar a repetição regular de alguns eventos durante o período de estágio, como a chamada, o momento da leitura, da correção, da explicação, os momentos de entrada e saída de professor, estagiário, alunos e mesmo outros da sala de aula, ou seja, há determinadas situações escolares que nos remetem ao "ritual", que podemos dizer que se assemelham a rituais religiosos, como casamento ou missa/ culto, nos quais há determinados momentos que sempre se repetem a cada celebração.

A finalidade da análise dos dados, no presente texto, é obter um entendimento profundo do processo de observação-registro dos acontecimentos. Para isso, podemos contar com os estudos de Possenti (2009), que nos apresenta dois tipos de dados: os rentáveis e os cruciais.

Os dados rentáveis seriam os dados herdados, que, segundo o autor, são os corpora privilegiados pela tradição, como discursos emitidos por instâncias institucionais. O dado crucial, por sua vez, seria o dado retirado/dado de determinado lugar/espaço em que se presencia 
um acontecimento. Em nosso caso, podemos correlacionar este segundo dado ao processo de registro do estágio supervisionado no diário de observação/campo, de onde o estagiário retira inúmeros dados da realidade, na qual ele próprio se vê inserido e a qual expõe ao leitor.

Neste trabalho, os diários e relatórios estudados forneceram dados cruciais e rentáveis, nos quais observarmos respectivamente o processo de registro ao longo das observações e reflexões feitas a posteriori, tendo por base os dados coletados. Para a elaboração dos diários e relatórios nos cabe trazer à luz a seguinte reflexão-registro: "[O] dado é freio para a divagação sem sentido, descontrolada. Sua existência impede o analista de fabricar seu objeto, impede o analista de defender atitudes subjetivistas" (Possenti, 2009, p. 29).

No momento do registro dos dados, trava-se um embate entre o aluno pesquisador e o texto escrito, tendo em vista a diversidade de acontecimentos que ocorrem simultaneamente e a forma como serão registrados, o que nos remete a uma reflexão feita por Todorov acerca do tempo do discurso e do tempo da história, muito reveladora dessa angústia no momento da passagem da observação para a escrita:

O tempo do discurso é, num certo sentido, um tempo linear, enquanto que o tempo da história é pluridimensional. Na história, muitos eventos podem desenrolar-se ao mesmo tempo. Mas o discurso deve obrigatoriamente colocá-los um em seguida a outro; uma figura complexa se encontra projetada sobre uma linha reta (Todorov apud Nunes, 2000, p. 27).

Relativamente ao registro ao longo das observações, podemos pensar ainda em Percy Lubbock (apud Leite, 1993), cujos estudos encaminharam-se para a distinção entre narrar (telling) e mostrar (showing), que tem a ver com a intervenção ou não do narrador. No processo do registro escrito do estágio supervisionado, podemos dizer que o aluno pesquisador ocupa esse papel de narrador, e, completando essa dupla "narrar e mostrar", temos a oposição entre cena e sumário (panorama). Leite (1993, p. 14) nos traz os seguintes detalhamentos para tais oposições: "Na CENA, os acontecimentos são mostrados ao leitor, diretamente, sem a mediação de um NARRADOR que, ao contrário, no SUMÁRIO, os conta e os resume; condensa-os, passando por cima dos 
detalhes e, às vezes, sumariando em poucas páginas um longo tempo de HISTÓRIA".

Considerando o trecho anterior, observamos que o trabalho do estagiário permeia os dois campos das oposições, mas o objetivo primeiro é trazer a cena ao leitor, para que seja posto em sua forma mais crua o que foi observado e no maior número de detalhes possível. O aluno-pesquisador, digamos "narrador", não deve comandar os movimentos dos partícipes, o tempo cronológico, o espaço e a linguagem a partir dos quais os fatos se expressam, como se fosse um autor implícito, o qual faz uso desses artifícios para manipular os diversos níveis da narração. É premente que o aluno-pesquisador dê, de fato, voz aos partícipes.

Tendo em vista o que foi exposto, veremos algumas passagens, na seção "Resultados e Discussões", em que o aluno-pesquisador, ao longo do estágio supervisionado, demonstrou dificuldades no registro escrito.

\section{Método de Pesquisa}

O presente artigo buscou analisar a escrita nos diários e relatórios de estágio das disciplinas de Metodologia do Ensino de Língua Portuguesa I (MELP I) e Metodologia do Ensino de Língua Portuguesa II (MELP II), elaborados pelos alunos de graduação do curso de Letras ${ }^{6}$ da Universidade de São Paulo (USP), destacando os pontos que apresentam problemas de formalização escrita, tendo à luz o conhecimento adquirido nas duas disciplinas e nos livros, dentre aportes teóricos diversos, apontados na referência bibliográfica, que auxiliaram no processo de coleta e análise dos dados.

Para realizar o levantamento dos dados, contou-se com o banco de dados "Metodologias", que armazena e organiza os relatórios e diários selecionados para o presente trabalho. $\mathrm{O}$ banco de dados conta com 55 diários e respectivos relatórios entre os anos de 2010 a 2014, dos quais 37 são apenas da disciplina de Metodologia do Ensino de Língua Portuguesa (13 de MELP I e 24 de MELP II).

Para o presente trabalho, foram escolhidos 3 diários e seus respectivos relatórios para a coleta de dados, os quais traziam dados relevantes para a análise bem como a sua frequência em outros diários e relatórios que não foram escolhidos, perfazendo o total de 171 laudas

6 Os alunos de graduação da Letras tiveram seu ingresso pela Faculdade de Filosofia, Letras e Ciências Humanas (FFLCH-USP), porém as matérias da Licenciatura são cursadas na Faculdade de Educação (FE-USP). 
analisadas. Foram detectados 114 pontos de imprecisão, invisibilidade e branquidão ${ }^{7}$ nos documentos analisados.

Haja vista a quantidade de pontos de imprecisão detectados, para o presente artigo foram selecionados alguns desses pontos, com o objetivo de otimizar a análise proposta e em virtude de haver pontos que se assemelham no próprio documento ou ainda se assemelham com as dificuldades encontradas nos outros diários e relatórios contemplados.

Os três informantes cujos trabalhos foram escolhidos são alunos já egressos do curso de Letras - Bacharelado e Licenciatura - da Faculdade de Filosofia, Letras e Ciências Humanas (FFLCH) da USP. Seus diários e relatórios do estágio supervisionado foram desenvolvidos para a disciplina de MELP I e MELP II: os informantes 1 e 2, para MELP II, respectivamente nos anos de 2010 e 2011, ao passo que o informante 3 desenvolveu o diário e o relatório para MELP I no ano de 2014.

Para fins elucidativos, informamos que, no item a seguir, que trará os fragmentos selecionados, utilizaremos algumas siglas para identificá-los, e os trechos extraídos serão transcritos em itálico. Segue quadro com as siglas:

\begin{tabular}{|l|l|}
\hline $\begin{array}{c}\text { Sigla/ } \\
\text { Identificações }\end{array}$ & \multicolumn{1}{c|}{ Significado } \\
\hline I1 & Informante 1 \\
\hline I2 & Informante 2 \\
\hline I3 & Informante 3 \\
\hline MELP1 & Metodologia do Ensino de Língua Portuguesa I \\
\hline MELP2 & Metodologia do Ensino de Língua Portuguesa II \\
\hline 2010 & Ano em que foi produzido o documento \\
\hline F1 & Fragmento ${ }^{\circ}$ (para localizar e distinguir os fragmentos) \\
\hline $\mathrm{D}$ & Diário de campo/ observação \\
\hline $\mathrm{R}$ & Relatório de estágio \\
\hline & Quadro 1: siglas utilizadas neste trabalho \\
\hline
\end{tabular}

Desta forma, quando o leitor se deparar, por exemplo, com a seguinte sigla "I2 MELP2 2011 F15 R", significa que o fragmento número 15 foi retirado do relatório de estágio elaborado pelo informante 2 para a disciplina de MELP II (Metodologia do Ensino de Língua Portuguesa II) no ano de 2011.

7 Lacuna. 
Assim, por meio da análise dos diários e relatórios, procurou-se verificar como o graduando em Letras lidava com o objeto de estudo. O método utilizado para a coleta de dados seguiu os seguintes critérios: descritivo, etnográfico, explicativo, exploratório, comparativo e interpretativo.

\section{Resultados e Discussão}

\section{a) Informante 1}

No diário do Informante 1 (I1) ${ }^{8}$, verificaram-se informações gerais da unidade escolar observada, tais como: aspectos físicos e institucionais (a necessidade de usar crachá e a não obrigatoriedade de usar uniforme), localização da escola, a formação do professor que aceitou o estagiário, e a série ${ }^{9} \mathrm{em}$ que foram feitas as observações. No relatório, por sua vez, não há a apresentação do cenário escolar em que foi feito o estágio e alguns trechos que foram retirados do diário não traziam indicação de data, série ou aulas em que foi feita a observação. Salientamos que as páginas indicadas dos trechos retirados do diário que constavam no relatório não correspondiam, possivelmente em virtude de o I1 ter juntado os dois documentos e não os ter renumerado.

As lacunas assinaladas mostram que o licenciando em questão tomou o relatório e o diário como documentos distintos e independentes, quando, na verdade, ambos se completam. O relatório, por constituir o "trabalho final" da disciplina, deveria trazer dados do diário, para que o leitor se situasse com maior precisão no espaço e tempo que lhe são apresentados, e quem sabe assim trazê-lo para a experiência vivenciada pelo observador.

Vale salientar que, no diário, percebemos que 43 aulas foram registradas na categoria observação. Já em relação à regência, não há nenhuma informação, seja no diário ou no relatório, o que nos deixa sem quaisquer informações sobre como foi realizada a regência.

No que tange às aulas observadas, não foram mencionados dados como: dia, mês, horário das aulas no cronograma escolar $\left(1^{\mathrm{a}}, 2^{\mathrm{a}}, 3^{\mathrm{a}} \ldots\right)$, e o período das aulas (matutino, vespertino, noturno). Com relação à última descrição, o leitor pode apenas deduzir que as aulas foram feitas no período matutino (ao menos na turma $8^{\mathrm{a}} \mathrm{D}$ ), em virtude do verbo "despertar", presente no seguinte fragmento: "Por se tratar da primeira

8 O Informante 1 elaborou o diário de observação e o relatório do estágio supervisionado no ano de 2010 para a disciplina de MELP 2.

9 Turmas do $8^{\circ}$ ano. 
aula do dia, a sala está em ritmo de 'despertar'. O que seria complicado noutro horário, hoje se passou sem maiores problemas." (I1 MELP2 2010 F28 D p. 50). Vale ressaltar que esse registro aconteceu na penúltima observação do diário, o que faz com que o leitor siga um caminho às escuras durante algum tempo.

Um ponto a destacar é o momento da chamada: dentre as aulas observadas pelo I1, ela foi mencionada de modo genérico em sete aulas ( 2 aulas duplas e 3 aulas unitárias), dentre as quais podemos trazer os seguintes fragmentos: "A porta é fechada. E. ${ }^{10}$ faz a chamada. Os alunos estão agitadíssimos." (I1 MELP2 2010 F31 D p. 31); "Mal é feito [sic] a chamada. A lista é entregue à monitora, para que visualmente anote quem faltou." (I1 MELP2 2010 F32 D p. 44); "A chamada termina sob tumulto" (I1 MELP2 2010 F33 D p. 44); e "Chamada." (I1 MELP2 2010 F34 D p. 51).

Observamos que, além da forma genérica com que o evento da chamada é tratado, não há uma situação temporal e circunstancial apresentada ao leitor, ou seja, quando começou e terminou, o que ocorreu ao longo da chamada, como os partícipes se comportaram, o tom de voz empreendido (se foi feita em voz alta), e como foi feita a organização da turma em momentos de agitação.

Outra lacuna percebida no diário e no relatório é a ausência de um mapa de sala, o que possibilitaria saber a quantidade e a disposição espacial dos alunos nas turmas observadas e a posição do observador, ao longo das aulas. Devido à ausência dessa informação, deparamo-nos com imprecisões que podem ser ilustradas pelos seguintes fragmentos: "A $8^{\mathrm{a}} \mathrm{C}$ tem o menor número de alunos em relação a [sic] outras oitavas (30), no entanto fica numa das duas maiores salas da escola" (I1 MELP2 2010 F14 D p. 43); "Numa rápida olhada percebo que pouco mais da metade está com livro" (I1 MELP2 2010 F19 D p. 45); "Sou apresentado, apresento-me e procuro um lugar para sentar. Desta vez acho um lugar vazio no fundo." (I1 MELP2 2010 F13 D p. 29).

Diante desses excertos, não sabemos quantos alunos tem a $8^{\mathrm{a}} \mathrm{C}$ (F14), não sabemos a quantidade de alunos que frequentavam as aulas diariamente, já que não há esta informação nos registros das observações ou mesmo mapas de aula, além do mais, quando o I1 registra "numa das duas maiores salas da escola", perguntamo-nos: Quantas

10 Menção ao professor. 
salas a escola tem? Já no F19, não sabemos quantos livros havia na sala e, por fim, após 39 aulas observadas, faltando 13 para terminar a observação, o observador menciona, genericamente ${ }^{11}$, o lugar onde se sentou (F13); nas aulas que precederam essa, não sabemos a localização do observador dentro da sala de aula. No F13, o leitor fica ainda sem saber como ocorreu a apresentação, o que foi falado por parte do professor e do próprio estagiário, e se houve alguma pergunta dos alunos.

Quando se aborda a observação da sala de aula, é necessário contemplar o cenário que nos é posto em sua complexidade. Ao longo da análise dos registros desse informante, portanto, observou-se a necessidade de se descrever mais os aspectos do ambiente e dos partícipes que estão envolvidos. Essas lacunas impedem que a cena descrita seja vivenciada em sua plenitude e se torne material de reflexão para o leitor do texto.

No diário de observação do I1, percebeu-se que, das 43 aulas observadas, em apenas 3 aulas ${ }^{12}$ o aluno-pesquisador anotou o conteúdo passado na lousa. Por outro lado, o aluno apresentou anexos que continham páginas fotocopiadas do livro didático ${ }^{13} \mathrm{e}$ atividade de um aluno ${ }^{14}$, porém mesmo aí foi constatada uma grave lacuna: não há qualquer menção, seja no diário ou no relatório, a respeito da(s) aula(s) a que se referem cada um dos materiais anexados. Portanto, os anexos perdem a utilidade de retomar os conteúdos ministrados em cada aula.

Ressalto que, em determinados momentos do registro, o aluno mencionou a página 26 da apostila: “(...) E. pede que abram a apostila da SEC na página 26. Lê em voz alta as definições de resenha que também estão lá, em seguida pede que comecem a fazer o exercício que está na mesma página." (I1 MELP2 2010 F34D, p. 51). Observamos que tal página não se encontra anexa, e, nas observações anteriores, não há menção ao conteúdo da página em questão, sobre a qual sabemos apenas que aborda "definições de resenha".

Desta forma, trava-se um impasse: há, nos anexos, folhas que não foram citadas nas observações do diário, e, inversamente, há, nessas

11 Uso "genericamente", porque o fundo da sala é bem amplo, sentou-se no centro, na esquerda ou na direita?

$128^{\circ} \mathrm{D}-1$ aula - p.41 e $8^{\mathrm{a}} \mathrm{A}-2$ aulas - pp.23, 25 e 26.

13 pp. 53-72, 20 (I1 MELP1 2010 - Anexos). Não há no trabalho a indicação bibliográfica do livro didático utilizado, o que inviabiliza, ao leitor, recuperar os conteúdos abordados naquelas aulas.

14 pp. 73-77 (I1 MELP1 2010 - Anexos). 
mesmas observações, menção a textos e a páginas da apostila que não foram anexados.

No que tange à ausência de anotações referentes ao conteúdo da lousa, podemos trazer o seguinte excerto: "[O professor] Escreve na lousa 'Resenha', pergunta se alguém sabe o que é. Vêm muitas respostas como 'É um texto, tipo assim, é... tipo falar de um filme que você viu na televisão, tipo um livro que você leu'. E. põe uma definição curta na lousa e pede para copiar." (I1 MELP2 2010 F23D, p. 47). Após tal passagem, perguntamo-nos: Que definição foi essa? Por que o observador não copiou a definição da lousa? É possível que, com tais informações, pudéssemos ver se a definição se aproximava das respostas dos alunos. Ademais, não há registros de explicação do professor, ou seja, será que ele só perguntou para os alunos o que eles achavam e escreveu a definição? Houve conexão ou desconexão entre o que foi anotado na lousa e o que os alunos responderam? Foi valorizada a resposta dos alunos, ou descartada? Devido a essa lacuna no registro, não é possível saber como se desenrolou essa prática docente, e torna-se impossível avaliar a eficácia pedagógica desse evento.

As lacunas de informações, sejam em menor ou maior número, descontextualizam a realidade observada e inviabilizam um acesso aos verdadeiros problemas existentes no processo de ensino-aprendizagem. Sem um detalhamento e um apuro no momento da descrição, não há como resolver os problemas latentes ou patentes em cada turma observada. A falta de método no registro escrito impossibilita o encadeamento dos acontecimentos para o leitor, e não permite se chegar a conclusões precisas para uma tomada de ação.

Em outra passagem do I1, há um fragmento relacionado à leitura no qual o observador tece comentários generalistas e imprecisos ao usar o advérbio "aparentemente":

E. anota algo em sua planilha e pede a outra pessoa para continuar a leitura. A garota que não queria ficar só também reluta em ler. Quando começa o faz com extrema dificuldade. [sic] Gagueja muito, aparentemente não por timidez, pelo visto ela não sabe ler. Porém, não foi a única a demonstrar embaraços na leitura, outros também, mas o caso dela foi o mais sublinhado (I1 2010 MELP2 F3R, p. 4). 
Haja vista a passagem, pergunta-se: A garota não queria ler sozinha? Pensou que leria o texto sozinha?, "A aluna disse algo que pudesse corroborar tal registro? Em um segundo momento, pergunta-se como o aluno-pesquisador chegou à conclusão de que a aluna não sabia ler.

O I1 registra "o faz com extrema dificuldade" e "não foi a única a demonstrar embaraços". A impressão é que tais construções parecem remeter a alunos que, embora saibam ler, têm dificuldades, fazendo cair por terra a construção: "pelo visto ela não sabe ler". Se a aluna fez a leitura, não obstante tê-lo feito com extrema dificuldade, compreende-se que algo foi lido, e, portanto, a aluna sabe sim ler.

A fim de esclarecer tal evento, o aluno-pesquisador poderia ter perguntado ao professor - prévia ou posteriormente a esse evento - se havia alunos que não liam naquela turma e se de fato a aluna em questão apresentava essa lacuna de letramento, de modo a não depender de suposições subjetivas sem real fundamento.

\section{b) Informante 2}

Ao partir para a análise do diário e do relatório do Informante 2 (I2) ${ }^{15}$, foi possível observar que o presente aluno acrescentou no diário mais informações: o aspecto físico da escola (presença de grades nas janelas, portas de aço, corredores, e salas relativamente amplas $)^{16}$, a localização da escola, as salas que acompanhou (3 turmas do $1^{\circ}$ e do $2^{\circ}$ ano do Ensino Médio $-1^{\circ} \mathrm{A}, 1^{\circ} \mathrm{C}$ e $\left.2^{\circ} \mathrm{B}\right)^{17}$, período em que foram observadas as aulas (matutino) ${ }^{18}$. Em suma, os dados do segundo informante (I2) apresentam mais descrições e informatividade.

O I2 observou 40 aulas e fez 22 regências. Todos esses eventos foram registrados exclusivamente na forma de discurso indireto, em contraposição ao I1, que utilizou tanto discurso direto como indireto, porém não registrou as regências. Para o registro, ambos os discursos são válidos e exigem detalhamento, para que o registro não paire na superficialidade, mas, no que toca ao registro das falas, o uso do discurso direto possibilita maior verossimilhança do evento presenciado.

15 O Informante 2 elaborou o diário de observação e o relatório do estágio supervisionado no ano de 2011 para a disciplina de MELP 2.

16 I2 MELP2 2011 D p.12

17 Idem.

18 Idem. 
O discurso direto traz em primeira mão a voz dos alunos (e de todos que aparecem na descrição das cenas), reproduzindo questionamentos, ameaças, agressão verbal e demais interações verbais da forma mais próxima possível à cena real, ao passo que o discurso indireto traz tão somente a perspectiva do observador, num pressuposto errôneo de onisciência e onividência na narração dos fatos observados. Defendemos, portanto, que o discurso direto seja usado com a maior frequência possível e de forma preferencial nos registros escritos do estágio.

Outro fato a destacar no trabalho do I2 é o registro da quantidade de alunos, que apresenta imprecisão em determinados momentos. Das 40 aulas observadas, apenas na primeira é fornecida ao leitor a quantidade precisa de alunos em sala de aula "Há 25 alunos na sala" (I2 MELP2 2011 F57 D p. 13). Posteriormente, em seis aulas duplas e uma aula avulsa, perfazendo um total de 13 aulas, foi mencionada a quantidade de alunos de modo impreciso: "Havia cerca de 30 alunos." (F50, p. 14); "(...) pelo que contei havia uns 35 alunos" (F51, p. 24); "Quando chegamos havia por volta de uns 27 alunos que eu contabilizei." (F52, p. 33-34); “(...) havia por volta de 29 alunos.” (F53 e F54, p. 45 e 47); "(...) havia por volta de 30 alunos" (F55, p. 50); e "Quando chegamos havia por volta de 31 alunos." (F56, p. 51). Nas demais aulas observadas não foram registradas a quantidade de alunos.

Diante de tal situação, nos questionamos sobre o porquê da imprecisão ou da ausência de registro quanto ao número de alunos presentes em sala de aula, se esse fato poderia ter sido resolvido a partir de um mapa de sala elaborado pelo observador, onde o aluno-pesquisador registraria os alunos presentes na aula de acordo com o lugar em que estavam sentados ou mesmo a partir da chamada registrada pelo professor poderia obter esse quantificador.

Essa abordagem numérica aparece também em outros dois momentos do diário: "Nesta sala alguns poucos alunos, em média 10, entenderam mais ou menos os conceitos e exemplos de preposição e conjunção, mas a maioria tem dificuldade até mesmo de identificar algumas vezes o que é um verbo na oração." (I2 MELP2 2011 F10 D p. 21) [grifo meu]. Após a leitura de tal fragmento, tendo em vista o quantificador "em média", o leitor pode questionar-se como foi possível chegar a essa média de 10 alunos e como chegou à conclusão de terem entendido "mais ou menos". O observador inquiriu tais alunos? Foi o semblante dos alunos que expressou sua incompreensão do assunto 
abordado pelo docente? Ou os alunos interagiram e foram ratificados pelo professor?

Outro tópico que o I2 se propõe a registrar no diário de observação é a chamada. Em seus registros, esse evento de sala de aula foi mencionado com frequência: em 15 aulas duplas (30 aulas) e 6 aulas unitárias, perfazendo 36 aulas, contrastando com as anotações feitas pelo I1, que só registrou esse procedimento em sete aulas. Cabe apontar que, dentre esses registros do I2, ora a chamada foi mencionada de modo genérico, ora de forma mais descritiva. Vejamos alguns fragmentos:

\begin{tabular}{|ll|l|}
\hline $\begin{array}{c}\text { Identificação } \\
\text { (I2 MELP2 2011) }\end{array}$ & \multicolumn{1}{c|}{ Fragmento } \\
\hline F30 & D, p. 18 & $\begin{array}{l}\text { "Após ter se acomodado na sua mesa, pega o diário de } \\
\text { lasse e inicia a chamada. Finda a chamada, cobra dos } \\
\text { alunos os trabalhos que ficaram de entregar nesta presente } \\
\text { data." }\end{array}$ \\
\hline F32 & D, p. 21 & $\begin{array}{l}\text { "A professora K. inicia a chamada, tudo corre } \\
\text { aparentemente como nos demais dias, conversas paralelas, } \\
\text { etc. A professora [sic] após a chamada, faz comentários da } \\
\text { vida pessoal de algumas alunas" }\end{array}$ \\
\hline F36 & D, p. 27 & $\begin{array}{l}\text { "Como costumeiramente faz, inicia a chamada e após a } \\
\text { chamada pede a uma aluna que transcreva o conteúdo na } \\
\text { lousa (...)" }\end{array}$ \\
\hline F37 & D, p. 29 & $\begin{array}{l}\text { "Ela fez a chamada, e logo em seguida pediu aos alunos } \\
\text { [sic] copiassem a matéria da aula anterior (...)" }\end{array}$ \\
\hline F44 & D, p. 42 & $\begin{array}{l}\text { "A professora dá bom dia, e alguns respondem. Inicia } \\
\text { a chamada, como de costume, quase que erra o diário, } \\
\text { pois insistiu em um nome que não era daquela sala, logo } \\
\text { que percebeu o equívoco, desculpou-se, e é claro que os } \\
\text { sarcasticamente deram risada. } \\
\text { Após a chamada a professora K. disse que daria um outro } \\
\text { texto (...)" }\end{array}$ \\
\hline F46 & $\begin{array}{l}\text { "A professora K. dá bom dia, e os alunos respondem. } 4 \\
\text { Após a chamada, diz que hoje verão os exercícios de } \\
\text { interpretação (...)" }\end{array}$ \\
\hline
\end{tabular}




\begin{tabular}{|c|c|}
\hline F33 D, p. 22-23 & $\begin{array}{l}\text { "Enquanto a professora faz a chamada, tem muita } \\
\text { conversa, havia umas alunas ao meu lado que insistiam em } \\
\text { fazer perguntas da minha vida pessoal, e eu, naturalmente, } \\
\text { tentava desviar a atenção delas para a chamada e [sic] sala } \\
\text { de aula. } \\
\text { Realizada a chamada, a professora K., como de costume } \\
\text { [sic] pede a uma aluna para passar o conteúdo daquelas } \\
\text { aulas." }\end{array}$ \\
\hline F43 & $\begin{array}{l}\text { "A professora K. inicia a chamada, pede que permaneçam } \\
\text { em silêncio e prestem atenção, alguém grita no fundo } \\
\text { presente [sic], sem ter sido chamado, nem eu nem a } \\
\text { professora K. conseguimos identificar a pessoa. } \\
\text { Ela prossegue com a chamada, após o seu fim, diz que hoje } \\
\text { os alunos aprenderão sobre Regência nominal e verbal } \\
(\ldots) \text { (..)" }\end{array}$ \\
\hline F49 D, p. 51 & $\begin{array}{l}\text { "Ela vai até a sua mesa, e inicia a chamada. Alguns alunos } \\
\text { conversam e não prestam muita atenção na chamada, a } \\
\text { professora K. insiste que devem responder senão ficarão } \\
\text { com falta. } \\
\text { Após a chamada inicia a aula dizendo que hoje verão } \\
\text { o texto de Homem que é Homem de Luís Fernando } \\
\text { Veríssimo (...)" }\end{array}$ \\
\hline
\end{tabular}

\section{Quadro 2: referências à chamada no diário de observação do informante 2}

Tendo em vista os excertos apresentados, verificamos problemas relacionados a: precisão, detalhamento na descrição, ausência de temporalidade na narrativa e desconexão com passagens que as antecedem.

Ao refletir sobre tais orientadores, podemos verificar que $-\mathrm{em}$ F30D, F32D e F36D - a chamada é registrada de modo genérico, pois há apenas o registro do início e do fim da chamada. O leitor fica sem saber como transcorreu tal procedimento, que pode requerer intervenção do(a) docente conforme as atitudes da turma. Está ausente também a menção a como os partícipes se comportaram nessa situação (se falaram, ficaram em silêncio ou levantaram, ou mesmo se foi necessário interromper a chamada, se foi retomada).

No fragmento 32D, por meio do escrito "[Professora] faz comentários da vida pessoal de algumas alunas", percebe-se a falta que faz o discurso direto, quando se deixou de dar voz à professora. Todas as 
informações que o aluno escutou, sobre a "vida pessoal de algumas alunas", perderam-se.

Ainda no fragmento F32D, e no fragmento F36D, por meio, respectivamente, das construções "tudo corre aparentemente como nos demais dias" e "Como costumeiramente faz", chamamos atenção para o caráter genérico de ambos os registros: o ideal é que cada aula registrada traga tantos detalhes quanto a primeira, pois cada aula é um evento que comporta experiências e vivências únicas. Tais construções evidenciam um ponto falho no registro, que é a generalização, quando, na verdade, o que deve se prezar, nas anotações sobre as aulas, é a objetividade das cenas. Quando a perspectiva subjetiva se sobrepõe a um relato objetivo, há prejuízo ao registro dos fatos e ao conteúdo informacional compartilhado com o futuro leitor desses documentos.

Em F37D e F46D, não sabemos quando teve início a chamada. Em F46D, decorridos alguns fatos da aula, o observador registra repentinamente: "Após a chamada", e, em F37D, o observador utiliza o verbo "fazer" no pretérito perfeito, onde detemos apenas a informação pontual de que a chamada ocorreu. Por fim, em F46D, quando o observador registra “(...) os alunos respondem.", podemos nos questionar: Todos os alunos responderam? Novamente, a objetividade do relato esbarra na falta de detalhamento e no tratamento genérico do que decorreu. Quando a professora disse bom dia à turma, todos responderam imediatamente? De que forma os alunos responderam?

No fragmento $44 \mathrm{D}$, o observador relata com mais detalhes apenas o momento em que a professora pega o diário errado para fazer a chamada. Uma pergunta que pode emergir em virtude do registro do observador é: esse mesmo engano da professora ocorreu em mais vezes? Isso porque não há outro registro, ao longo do diário, que mostre esse mesmo equívoco da professora, e tampouco o licenciando se preocupou em fazer esse esclarecimento. No F44D, quando se diz: "e é claro que os alunos sarcasticamente deram risada" [grifo meu], podemos nos questionar ainda: o aluno-pesquisador abona a atitude dos alunos, pelo equívoco da professora? É importante enfatizar que as observações realizadas no estágio sempre trazem implicações éticas.

O segundo momento deste fragmento (F44D), que seria a chamada propriamente dita - após a professora ter pego o diário correto - é apagado. Tendo em vista a confusão e a troca de diário deduz-se que foi necessário iniciar a chamada outra vez, contudo o observador se limita 
a registrar: "Após a chamada (..)". Repete-se, aqui, o mesmo procedimento de não fazer apropriadamente as descrições, como foi verificado em F46D, onde não é possível saber sobre o início da chamada e como ela transcorreu. Como solução a essas lacunas de registro, podemos pensar na seguinte possibilidade: "Após o equívoco da professora, ela pegou o diário correto e recomeçou a chamada. Ao iniciar a chamada, ... Durante a chamada, ..."

Assim como nos relatos anteriores, suponho que, em virtude do equívoco da professora, esta chamada não ocorreu tranquilamente, até mesmo por conta de o observador caracterizar o ânimo da sala no parágrafo seguinte como "agitada", por meio do seguinte excerto "A sala estava um pouco agitada, mas a professora K. pareceu não se importar (I2 MELP2 2011 F68D p. 42).” Cabia ao estagiário, todavia, descrever essa agitação, objetivamente, assim como sua impressão que teve da atitude da professora, de suposta indiferença.

No quadro 2, é possível verificar fragmentos que contêm mais descrições do evento observado. É relevante trazê-los, para mostrar que o aluno também faz registros mais completos - o que falta é manter um método contínuo e consistente para o registro.

Nos fragmentos F33 D, F43 D e F49 D, percebe-se que há a indicação do início e do término da chamada. O comportamento dos partícipes é descrito, há a indicação das pausas que foram necessárias, dentre outros elementos que corroboram para a visualização da cena.

Dentre os fragmentos apontados no parágrafo anterior, é possível encontrarmos algumas lacunas, como na passagem do fragmento F33D em que o observador registra: "(...) havia umas alunas ao meu lado que insistiam em fazer perguntas da minha vida pessoal (...)". Reitera-se a importância do uso do discurso direto, como forma de responder a questão: Quais perguntas, especificamente, lhe foram feitas?

Por fim, o informante 2, no momento da regência, restringiu-se ao conteúdo das aulas, e, ainda assim, com lacunas, em observações como estas: "Continuidade da aula anterior" (p. 55), “(...) ministrei o mesmo conteúdo (...) a recepção da aula me pareceu a mesma" (p. 55), além de não constar o registro das impressões dos alunos (comentários que fizeram durante a regência, sua recepção e interação), o que impede o leitor de ter uma visão inteiriça da observação. 


\section{c) Informante 3}

Analisamos, aqui, o relatório e o diário elaborados pelo Informante 3 (I3) ${ }^{19}$, o último informante contemplado neste artigo. Em seus registros, pode ser apontado, em um primeiro momento, que o aluno-pesquisador menciona, no relatório, o nome da escola, sua localização, as séries observadas ( $4^{\circ}$ e $5^{\circ}$ anos), contudo não especifica quantas e quais turmas foram observadas.

O observador também não traz aspectos físicos e institucionais da unidade escolar observada, e não indica quantas horas de estágio (observação e regência) foram efetivamente realizadas. Vale salientar que o diário de observação do informante só traz o registro de cinco aulas observadas. Não há, tampouco, registro da regência, e as aulas observadas contidas no anexo não estão na íntegra. Podemos verificar este último fato no seguinte excerto, cuja estrutura se repete nas outras aulas observadas que estão registradas no trabalho: "Esse trecho de aula selecionada mostra como as aulas de gênero do discurso funcionam: (I3 MELP 12014 F1D p. 9)”.

Tendo em vista esse fragmento, que se encontra na primeira observação registrada, percebe-se, nesse preâmbulo, que o observador recorta para o leitor apenas uma parte pouco específica relacionada ao conteúdo, dentro de um cenário muito mais amplo e que não se circunscreve apenas a este ou aquele foco de observação escolhido a priori pelo aluno. É relevante apontar o ideal de que a observação da aula seja trazida na íntegra, caso contrário, nos deparamos com o apagamento de outros fatos, que, desconsiderados pelo observador, tornaram-se, portanto, invisíveis e inacessíveis aos olhos de um possível futuro leitor. Outrossim, tal restrição na escolha do que vai relatar prejudica a compreensão do desenvolvimento da aula, impedindo que o texto fique claro e encadeado.

Constata-se que o informante 3 não apontou a quantidade de alunos, o período das aulas (manhã, tarde ou noite), e, em determinadas aulas, deixou de apontar a data de quando ocorreram. No diário exposto pelo I3, verificamos a presença da chamada em apenas um momento: "A atividade é a continuação da reescrita da carta fictícia. Denise faz

19 O Informante 3 elaborou o diário de observação e o relatório do estágio supervisionado no ano de 2014 para a disciplina de MELP 1. Salienta-se que o informante não colocou numeração nas páginas, portanto, quando houver menção de página, a referência numérica é de nossa própria autoria, a partir da sequência do arquivo. 
a chamada, os alunos estão silenciosos, e respondem a chamada enquanto começam sua atividade. Ela é firme durante a aula. Uma aluna pergunta sobre a margem da folha (I3 MELP1 2014 F29D p. 12)." Apesar de o evento apresentado trazer dados descritivos, como o silêncio e a chamada concomitante com o início da atividade, não são delimitados o início e o fim da chamada, tampouco o que quer dizer "uma aluna pergunta sobre a margem da folha", cuja interpretação fica obscura para o leitor do texto.

Por fim, a leitura do fragmento 19R traz algumas dúvidas. Vejamos o trecho:

O estágio consistiu em regência de aulas seguidas [sic] de observações no meio escolar, portanto, o que motivou o planejamento das aulas, e certas situações que me chamaram mais atenção, uma das principais notadas, foi a falta de criatividade em sala. Considero que a criatividade é um quesito importante a ser trabalho [sic] em qualquer área de ensino, a aula não pode estar engessada com a apostila, e tão menos deve ser uma repetição vazia de conteúdos. Isso ocorreu muitas vezes, não diria que exclusivamente (I3 MELP1 2014 F19R, p. 2).

Tendo em vista a passagem anterior, o leitor pode se perguntar: O aluno fez a regência antes da observação? Por que isso aconteceu, se a orientação é justamente fazer a observação primeiro e só depois a regência? Enfatizamos o registro: "Isso ocorreu muitas vezes", que se refere à alegada falta de criatividade e engessamento das aulas, o qual, entretanto, não evidencia indicadores dessa "falta de criatividade em sala". Quando o observador diz que "a repetição vazia de conteúdos ocorreu muitas vezes", espera-se que indique em quais circunstâncias e de que modo.

Se o observador testemunha alguma situação de ensino que julga ruim, sua incumbência é descrevê-la, preocupando-se em relatá-la com o máximo de integridade - e então deve montar uma contraproposta, para lidar com esse problema verificado no ensino do professor observado.

Algo que tem de estar claro a esta altura é que os licenciandos têm de se esforçar para descrever aquilo que enxergam como problemas no processo de ensino-aprendizagem observado no espaço escolar, para atuarem com precisão cirúrgica nas questões verificadas. Comentários 
generalistas não auxiliam na busca por soluções. E, para se ter certeza de que o problema está sendo resolvido, é preciso que ele esteja, antes de tudo, bem descrito e visualizado.

\section{Conclusões}

É possível perceber no estágio supervisionado a dificuldade de se registrar os acontecimentos, tendo em vista os inúmeros fatos que ocorrem simultaneamente e em rápida sucessão em uma sala de aula, exigindo tanto agilidade nas anotações quanto capacidade mnemônica. Outro ponto de dificuldade é o fato de o trabalho do estagiário permear dois campos: ora sua presença em sala de aula é invisível, ora é visível e a ele cabe a responsabilidade de esforçar-se pela "invisibilidade", para que seja capaz de reconstruir com calma, clareza e fidelidade os acontecimentos vivenciados.

Além dos campos da visibilidade e da invisibilidade, o aluno-pesquisador, no momento do registro, adentra outros dois campos, o do "narrar" e o do "mostrar", e, neste embate, torna-se essencial que o aluno-pesquisador narre de forma que a cena seja apresentada ao leitor, a princípio sem a intervenção subjetiva do observador, com o intuito de registrar o evento em sua ocorrência própria e levar ao leitor o maior número possível de detalhes.

Ao longo desse processo, para que o aluno-pesquisador não se perca nos campos que permeia ao longo dos registros, torna-se de suma importância respeitar os partícipes envolvidos nas cenas observadas, desde a sua descrição física até a sua fala e modo como se expressam, e é necessário se preocupar com o fato de que o texto composto terá um futuro leitor, para quem todas as descrições têm de ser claras e completas em si próprias, para fazerem sentido.

O registro deve deixar claro e distinto o que é a voz do licenciando e o que é a voz dos agentes que ele observa. O registro não é lugar para deduções, incertezas ou generalidades. Esta modalidade de escrita é justamente o contrário: o espaço do específico, do detalhado, do evento etnográfico e antropológico observado com olhar científico e um punhado de dúvidas que darão lugar a algumas certezas e uma série de fatos, ao fim da observação.

No material analisado, observou-se a ausência de rigor científico e de método que estabelecessem constância nos dados, portanto, a variação na qualidade da observação é alta e isto prejudica a futura 
ação em sala de aula deste aluno-pesquisador, em vias de se tornar docente, bem como a sua própria ação de investigador na sala de aula e na universidade.

\section{Referências}

André, M. E. D. A. de. (2008). Etnografia da prática escolar. Campinas: Papirus.

. (1997a). Avanços no conhecimento etnográfico da escola. In: FAZENDA, Ivani (Org.). A pesquisa em educação e as transformações do conhecimento. 2. ed. Campinas: Papirus.

Angrosino, M.; FLICK, U. (Coord.). (2009). Etnografia e observação participante. Porto Alegre: Artmed.

Barzotto, V. H. (2014). Leitura, escrita e pesquisa em letras: análise do discurso em textos acadêmicos. Campinas, SP: Mercado de letras.

Brasil. (2006). Trabalhando com a educação de jovens e adultos - Observação e registro. Brasília: MEC/SECAD.

Fiorentini e Lorenzato. (2006). Investigação em Educação Matemáti$c a$ : percursos teóricos e metodológicos. Campinas, São Paulo: Autores Associados.

Foucault, M. (2009). O que é um autor? Lisboa: Passagens.

Freire, P. (1996). Pedagogia da Autonomia: saberes necessários à prática educativa. São Paulo: Paz e Terra.

Hammersley, M.; Atkinson, P. (1994). Etnografia: métodos de investigación. Barcelona: Paidós.

Leite, L. C. M. (1993). O foco narrativo (ou A polêmica em torno da ilusão). São Paulo: Ática.

Lima, M. C. (2000). Ensino com pesquisa: uma revolução silenciosa. São Paulo: M. C. Lima.

Lüdke, M. André, M.E.D.A. (1986). Pesquisa em educação: abordagens qualitativas. São Paulo: EPU.

Matos, C. L. G. de. (2001). A abordagem etnográfica na investigação cientifica. UERJ. Disponível em: http//www.ines.org.br

Nunes, B. (2000) O tempo na narrativa. São Paulo: Ática.

Possenti, S. (2009). O dado dado e o dado dado. In: Os limites do discurso: ensaios sobre discurso e sujeito. São Paulo: Parábola. 
Reis, P. Observação de aulas e avaliação do desempenho docente. Disponível em: http://www.ccap.min-edu.pt/docs/Caderno CCAP_2-Observacao.pdf

RiolfI, C. R., Barzotto, V. H. (Org.). (2014) Dezescrita. São Paulo: Paulistana.

Riolfi, C. R. (2010) Desafios na formação de professores de língua portuguesa in: Formação de professor de língua portuguesa: quando a linguagem e o ensino se encontram - Antonio Paulino de Sousa, Valdir Heitor Barzotto, Maria Lúcia Pessoa Sampaio (orgs.) - São Paulo: Paulistana (CAPES).

Vasconcelos, R. N. (2003). O sentido e o significado do registro para o professor e a professora. Educação em Foco (Belo Horizonte. 1996), Belo Horizonte, n.7, pp. 70-73.

Zaidan, S. e Tomaz, V. S. (org.). (2012) APEM - Análise da Prática e Estágio de Matemática. Disponível em: http://www.mat.ufmg. br/ead/acervo/livros/Analise $\% 20 \mathrm{da} \% 20$ Pratica $\% 20 \mathrm{e} \% 20$ Estagio $\% 20$ de $\% 20$ Matematica.pdf 
